\title{
Migración, maíz y silencio. Aproximaciones al bilingüismo (quichua- español) de los trabajadores 'golondrina' de Santiago del Estero (Argentina)
}

Migration, maize and silence. An approach to bilingualism (Quichua-Spanish) of 'swallow' migrant workers from Santiago del Estero (Argentina)

\section{Héctor Andreani}

Becario del Consejo Nacional de Investigaciones Científicas y Técnicas (CONICET). Universidad Nacional de Santiago del Estero (UNSE). Santiago del Estero, Argentina.

hectoralfredoandreani@yahoo.com.ar

\begin{abstract}
RESUMEN
Los escasos estudios sociolingüísticos referentes a la variante quichua hablada en Santiago del Estero (Argentina), diagnostican una situación de desplazamiento de dicha lengua, en beneficio del español. Visto como un proceso complejo y significativo al perfil macro-sociolingüístico de poblaciones nativas/migrantes de Argentina, describimos un caso de bilingüismo situado que no ha sido suficientemente abordado como factor sociolingüístico relevante. Se trata de miles de 'golondrina', o trabajadores rurales migrantes estacionales (TRME): una fuerza laboral subregistrada por empleadores multinacionales, que viaja a la pampa húmeda argentina para la 'desflorada' (despanojado) de maíz. A través de un abordaje antropológicosociolingüístico, este artículo explora dinámicas de interacción bilingüe (quichua-español) de los 'golondrina' provenientes de Santiago del Estero, estrategias de control laboral, microprocesos sociolingüísticos e ideologías lingüísticas que operan en el proceso de una socialización bilingüe.
\end{abstract}

\section{ABSTRACT}

The few sociolinguistic studies concerning the Quechua variant spoken in Santiago del Estero (Argentina) have assessed a language shift to the benefit of Spanish. Considering this as a complex process relevant to the macro-sociolinguistic profile of native-migrant populations in Argentina, we describe a case of located bilingualism which has not been sufficiently approached as a relevant sociolinguistic factor. We refer to thousands of migrant workers (referred to as 'swallows') or migrant seasonal farm workers (TRME in Spanish): an underemployed workforce recruited by multinational corporations who travel to the wet pampas of Argentina to take part in the 'deflowering' (detasseling) in the maize harvests. Through an anthropologicalsociolinguistic approach, this article explores the dynamics of bilingual interaction (Quichua-Spanish) of migrant workers ('swallows') who come from Santiago del Estero, the strategies of labor control, the sociolinguistic microprocesses and the linguistic ideologies that operate in a bilingual socialization process.

\section{PALABRAS CLAVE}

Trabajadores rurales migrantes estacionales (TRME) | lengua quichua | bilingüismo situado | estrategias de control | socialización lingüística KEYWORDS

Seasonal Migrant Rural Workers (TRME) | Quichua language | control strategies | language conflict | language socialization

\section{Introducción(1) (2)}

No puede haber una división social del trabajo sin su representación en la cultura.

Jean y John Comaroff

La variante dialectal es su única gran propiedad, la que frena el impulso a la marginalidad del modelo.

Eduardo Rosenzvaig 
Los escasos estudios sociolingüísticos referentes a la variante quichua santiagueña, que diagnostican o esbozan un cuadro de situación, son concluyentes en que ocurre un proceso de desplazamiento de dicha lengua, en beneficio del castellano (Alderetes 2001, Karlovich 2006, Albarracín 2009 y 2011). A partir de una mirada etnográfica que aporte a la complejidad de ese conflicto lingüístico, este trabajo describe un caso de bilingüismo situado (Unamuno 2004 y 2011, Sichra 2005) el cual, hasta la fecha, no fue suficientemente abordado como factor con implicancias sociolingüísticas de gran importancia. Se trata de los "golondrina" o trabajadores rurales migrantes estacionales (TRME).

Según estudios recientes, Santiago del Estero (SdE) es la provincia que más trabajadores migrantes provee a otras zonas agroproductivas de Argentina: de un total de 100.000 TRME que se trasladan de una provincia a otra, 35.000 son santiagueños (cf. Neiman 2009: 48). Esta fuerza de trabajo subregistrada -con bajos salarios, críticas condiciones laborales y subalternidad cultural- ha generado ganancias siderales de los empleadores multinacionales en relación con el pago al trabajador migrante (3). No obstante, siguen siendo decisivos en el espacio agrario nacional.

A través de un abordaje antropológico-sociolingüístico, en este trabajo proponemos explorar las dinámicas de interacción bilingüe (quichua y castellano) de los "golondrina" provenientes del departamento norteño de Figueroa y el departamento sureño de Salavina, a través de la compleja relación que estos TRME establecen con sus empleadores en el ámbito donde realizan la "desflorada" del maíz. Se describen las estrategias de control laboral, aspectos sociolingüísticos de estos trabajadores migrantes, y se indagan las ideologías lingüísticas (quichua y español), que operan en el proceso de una socialización bilingüe en medio de la trama laboral.

No son pocas las cuadrillas compuestas por trabajadores bilingües (4), pues provienen de zonas empobrecidas para la producción familiar sostenida, y la lengua quichua desde hace más de medio siglo que está asociada a la marginalidad rural (Albarracín 2009). Consideramos que esta franja es determinante por el número implicado de trabajadores (5) (una parcela significativa de esos 35.000), por el tiempo de socialización extra-familiar (20-60 días), y por el tipo de interacciones establecidas al interior del ambiente grupal (99 \% quichua según la apreciación de un trabajador, como veremos más adelante).

Este trabajo pretende ser un aporte a las escasas investigaciones con un enfoque (en general) sociolingüístico sobre la lengua quichua: desde el diagnóstico crítico (Albarracín y otros 1999, Alderetes y Albarracín 2004 y 2005), la lingüística descriptiva (Alderetes 2001, Albarracín 2009 y 2011), la sociolingüística de contacto (De Granda 2001), la lingüística comparada (Courthés 2003), la sociocrítica (Karlovich 2006, Andreani 2011) y la antropología (Grosso 2008). Creemos necesario complementar el enfoque de estas investigaciones "integrando la visión que los propios hablantes tienen respecto de los procesos sociolingüísticos que les afectan" (Wittig 2009: 141). Se trata de complejizar una mirada sociolingüística que, en su tarea de diagnosticar críticamente el desplazamiento de muchas lenguas minoritarias latinoamericanas, las proyecta como un objeto acumulativo que se pierde gradualmente en la mente de los hablantes (6). En consecuencia, debemos contemplar que las subjetividades bilingües pueden fluctuar de acuerdo con nuevos contextos de socialización lingüística, no sólo familiar, vecinal o escolar: en el caso de este trabajo, laboral extra-zonal. De ahí que "una mirada a los microniveles de los eventos comunicativos, sin embargo, nos revela que los procesos reales de desplazamiento y resistencia son mucho más complejos" (Hamel 1995: 81).

Para comprender este caso bilingüe, organizamos del siguiente modo: comenzamos con un acercamiento a la lengua quichua; posteriormente, un breve panorama de los trabajos que cruzan aspectos sociolingüísticos y laborales-migracionales, y las herramientas teórico-metodológicas recurridas; después describimos el trabajo de la desflorada de maíz hecho por los TRME, enfocando en las estrategias de control laboral. Además, indagamos usos e ideologías lingüísticas en conflicto entre trabajadores y empleadores; agregamos una breve escena de un trabajo (informal) de "desmonte" para comparar con la desflorada; y describimos usos no-conflictivos de la lengua. Finalmente, en las conclusiones exponemos las principales observaciones a las que hemos arribado. 


\section{Algunos aspectos del quichua santiagueño}

Santiago del Estero se encuentra en el corazón de la Argentina, en el vértice inferior del cuadrante noroeste (NOA) la zona más andina del país. El quichua es, paradójicamente, una "isla" lingüística que logró mantenerse cuando otras lenguas indígenas del NOA habían desaparecido pero sufrió, a su vez, un proceso de des-indianización durante el siglo XIX (Stark 1885), posiblemente a través de una subrepticia alianza entre clero, caudillos y campesinos contra el avance modernizador de la nación a fines del siglo XIX (Landsman 2000, Karlovich 2006). Este proceso sociohistórico habría permitido el mantenimiento del quichua en SdE, en tanto lengua "criolla". Este proceso se marcó históricamente con una perspectiva des-indianizada de la cultura folclórica en el siglo XX.

Respecto de la cantidad de hablantes de quichua, sobre un total de 896.461 habitantes en la provincia (INDEC 2010), y sin haber datos concretos ni censos confiables, se estima que solamente en SdE existen de 80.000 a 160.000 personas bilingües y otros 150.000 en Buenos Aires (Alderetes 2001), y una mínima porción en otras provincias. Casi la totalidad es bilingüe, aunque hay referencias vagas acerca de un monolingüismo en escasos ancianos. En SdE, hay un conglomerado étnico (indígenas, afroamericanos, europeos, criollos, árabes, judíos, etc.), no puede generalizarse como "quichuahablantes indígenas" (Albarracín y Alderetes 2004). Se estima que los bilingües se ubican en trece departamentos de la mesopotamia santiagueña (entre los ríos Dulce y Salado), viven en tierras poco favorecidas y sin desarrollo industrial (cf. Albarracín y Alderetes 2005), aún estando dentro del territorio productivo agro-ganadero.

Entre los hablantes del QS hay distintos gradientes de bilingüismo, desde aquellos que entienden pero no hablan quichua, otros con graduales dominios del QS, hasta una mayoría de los habitantes de SdE que no habla quichua. Hay una segunda variante, "la castilla" del sector bilingüe que es asumida como "diferente" frente a la variedad del español urbana. La "castilla" es tomada y expuesta por mayorías hegemónicas como auténticamente "santiagueña", frente a la forma de habla nacional. Aunque con atributos de subalternidad, el QS adquiere visibilidad (no-conflictiva) cuando es expuesta en usos culturalistas de la hegemonía política provincial.

\section{Antecedentes del cruce entre lengua quichua y trabajo migrante}

El trabajo rural migrante estacional ha sido abordado principalmente con una bibliografía más profusa, entre otros, en la literatura regional y los estudios laborales durante el siglo XX (Bialet Massé 2010 [1094]), desde una naciente sociología regional (Canal Feijóo 1951), y la sociología laboral (Biaggi et al. 2007, Desalvo 2009, Neiman 2009, Alberti y Martínez 2011, Ledesma y Tasso 2011). Las investigaciones sociolingüísticas refieren vagamente a las migraciones rurales, sin enfocar en el orden de los usos.

En un diagnóstico crítico sobre la situación educativa del quechua en el NOA, Lelia Albarracín (y otros 1999) refiere brevemente a las migraciones de santiagueños en la zafra de Tucumán, cuyo quichua contribuyó sustancialmente a la formación del español regional hablado en dicha provincia. Esto nos sugiere que, a una historia social del contacto lingüístico, vale agregar una etnografía histórica que reconstruya las prácticas efectivas de interacción de esos hablantes, cuya diversidad de situaciones sociolingüísticas (no registradas) exigen ser exploradas con otras dimensiones sociales que las afectan.

La introducción histórica en la gramática de Jorge Alderetes (2001), permitió dar a conocer por primera vez al público la idea de que el bilingüismo quichua-castellano se basaba en un conflicto socio-histórico de larga data, problematizando la tesis cristalizada de Domingo Bravo (1965) sobre una "convivencia" armónica de las dos lenguas. Precisamente Alderetes, en la búsqueda de un criterio razonable de estimación poblacional de quichuahablantes, llega a la problemática migracional. Para ello, cruza datos estadísticos porcentuales de santiagueños emigrados, junto con políticas de explotación forestal de comienzos del siglo XX. Dada esta problemática estructural intensa, concluye en que estas migraciones 
En un trabajo lingüístico descriptivo, Gerardo Lorenzino (2003) a partir de encuestas estructuradas a residentes santiagueños en Buenos Aires, explora los patrones socioculturales impactados por los procesos de migración, ya como residentes permanentes en dicha provincia. Observa una sustitución de construcciones sintácticas "como el gerundio perfectivo y el doble posesivo en la variante rural de los que se fueron [a Buenos Aires]" (2003: 59). Concluye que hay un abandono lingüístico, por la necesidad de integración a la sociedad hispanohablante porteña dominante, es decir "un desplazamiento lingüístico tanto a nivel intra- como intergeneracional si bien perviven ciertas tradiciones culturales" (Id: 59). Esta perspectiva prioriza una perspectiva camuflada del "rescate" lingüístico, sin indagar las perspectivas nativas sobre bilingüismo (Unamuno 2011). No se concibe el bilingüismo como un comportamiento lingüístico que responde "a las funciones de las lenguas en juego, no de la competencia lingüística de los hablantes" (Sichra 2005). Al postular la idea de "tener" una lengua e ir perdiéndola gradualmente, no contempla posibles contextos de socialización lingüística a lo largo del ciclo vital (Garret y Baquedano López 2002, Hecht 2010). Por ello, deben incluirse otras trayectorias vitales en el diagnóstico de una lengua minorizada.

Por último, nuestro antecedente más importante es el de José L. Grosso; su estudio antropológico sobre liminaridades identitarias en Santiago del Estero, refiere indirectamente a residentes santiagueños en Buenos Aires (Grosso 2008: 90). Basa su construcción de categorías en un mapeo general del territorio rural-urbano, eludiendo la terminología sociolingüística por un léxico hídrico-estratigráfico de las lenguas; su perspectiva certoniana aporta originalmente a la hipótesis de un conflicto lingüístico diverso. Consideramos nuestro trabajo como una profundización de una de las numerosas ideas propuestas por Grosso.

Por todo esto, vale preguntarnos, y las respuestas pueden (o no) arrojar un resultado más preciso: ¿qué niveles de interacción, contextos sociales, franjas etarias, trayectos grupales, ambientes de uso, y otros aspectos debemos tener en cuenta para "observar" el desplazamiento lingüístico? Debemos problematizar lo que, engañosamente, se presenta como un proceso de "gradual" des-acumulación lexical en la mente del bilingüe (merced a una vergüenza pasiva que domina todo su ciclo vital). La tesis del conflicto lingüístico, si bien permite problematizar las posturas chauvinistas secularizadas sobre la "armonía" entre lenguas (todavía hoy en boga), debe enriquecerse con datos etnográficos para un perfil más completo, o lo que sea que manifieste una lengua minorizada (sus hablantes) en su propio proceso dialéctico con el mundo social.

\section{Perspectivas teórico-metodológicas}

Este trabajo parte de un cruce entre herramientas antropológicas y sociolingüísticas. Si bien hemos acompañado procedimientos cuantitativos de otra experiencia (7), principalmente nuestro diseño es cualitativo pues no nos propusimos la saturación de datos, sino la elaboración de una trama socio-laboral significativa que permita ver el orden de los usos lingüísticos.

La mirada etnográfica sobre la lengua permite entender la integración lengua-vida social, así como comprender al lenguaje en cuanto recurso cultural y el habla cotidiana como práctica social (Duranti 2000). Recurrimos a entrevistas en profundidad (8), dado que por cuestiones particulares no pudimos realizar observación participante hasta el momento. Participamos en la vida cotidiana de los TRME en sus familias, en un clima de mucha cordialidad, no sólo en sus casas sino también en nuestra propia residencia (ciudad de La Banda, $100 \mathrm{~km}$. de Figueroa, y a $250 \mathrm{~km}$. de Salavina) que sirvió también de hospedaje necesario. Realizamos entrevistas a 5 jóvenes (17-21 años) y 5 adultos (23-60 años) del dpto. Figueroa, a 3 trabajadores golondrinas procedentes de la localidad de Villa Salavina (24-38 años), y numerosos diálogos informales durante 5 años (2006-2010) a 35 jóvenes que finalizaban sus estudios secundarios en un colegio del dpto. Figueroa. Este cúmulo de datos "sueltos" informales, fueron muy significativos para complementar la trama laboral propuesta (9). 
Recurrimos a un cruce teórico partiendo de que, aquello indagado como bilingüismo, debe ser necesariamente situado,

"emergente en la manera como los hablantes categorizan las formas verbales (...) en sus contextos locales de interacción social y en un marco etnográfico que hace posible su configuración; asimismo, implica un trabajo crítico respecto de la manera en que construimos el terreno de la investigación, sobre la producción de datos y sobre el rol del investigador" (Unamuno 2011).

Enrique Hamel $(1995 ; 2003)$ ve al lenguaje como un instrumento de poder social relacionado con las identidades colectivas, y propone organizar el análisis de las interacciones mediante marcadores de desplazamiento lingüístico, en tres niveles. Esto nos permite "visualizar" mejor algún aspecto lingüístico que estaría siendo desplazado: a) esquemas culturales (concepciones, habitus, estilos y organizaciones); b) patrones discursivos (pragmáticas, géneros discursivos, categorías conversacionales); y c) estructuras lingüísticas (niveles morfológicos, sintácticos, semánticos, variaciones sociolingüísticas).

A partir de la clásica perspectiva sobre hegemonía de R. Williams (1977: 112), Grosso observa que en SdE se conformó históricamente un bilingüismo táctico: por un lado, los quichuahablantes ejercen el discurso dominante en el silencio de su propia lengua; por otro lado, el bilingüismo fuerza a la hegemonía lingüística a que reconozca su naturaleza excluyente (Grosso 2008: 92). Esto implica un aspecto más complejo del "silencio" laboral (que veremos más adelante) inserto en un proceso hegemónico.

La ideología lingüística puede ser vista como mediación entre determinadas formas de habla con la estructura social (Woolard y Schieffelin 1994), emergiendo cuando se explicita un conflicto lingüístico (10) (Hamel 2003) en usos situados de lenguas, marcando límites, prohibiciones o aperturas. Para Carolina Gandulfo, la ideología lingüística opera como "generalización normativa que oculta los cambios de código que se realizan efectivamente en los ámbitos no propicios" (2007: 171). Por ejemplo, los primeros testimonios indicaban sólo reclamos hacia la prohibición lingüística de los capataces; posteriormente, ofrecían un cuadro más diverso de esas relaciones, (no siempre unidireccional) respecto de su propio "silencio". También estas ideologías pueden servir como marcación grupal, y sus modificaciones colectivas se vinculan a dichas ideologías (Makihara 2005). Nos interesa la propuesta clásica de Valentín Voloshinov (1929) entre ideologías objetivistas (lenguas formalizables e institucionalizables) y subjetivistas (lenguas estéticas, familiares, subjetivas, idealistas, intimistas); esto permite ver las asociaciones entre lenguas y ambientes laborales (formalidad-informalidad).

Por último, según la socialización lingüística, los sujetos de un sector (bilingüe o no) se socializan a través de la lengua, pero también en la lengua como proceso de reproducción cultural (Schieffelin y Ochs 1986) pero también como dinámica de transformación sociocultural (Garret y Baquedano-López 2002, Hecht 2010). Esto implica un proceso dinámico de agencia sociolingüística por parte de hablantes que se incluyen o son incluidos en la cuadrilla laboral.

\section{Condiciones laborales de la desflorada}

Un sector aproximado de 35.000 trabajadores "golondrina" o trabajadores rurales migrantes estacionales (TRME), viaja en cuadrillas de 15 a 19 hombres (incluyendo al jefe de cuadrilla y el cocinero) principalmente a la pampa húmeda y otras zonas para la desflorada (despanojado) de maíz, cosecha de aceitunas, arándanos, papas, desmonte o desenraizamiento. Respecto de las edades, "el trabajador más joven tiene 17 años y el mayor 62 (...) el mayor número de TRME se encuentra entre los 20 a 40 años de edad, con una concentración más fuerte entre los 25-35 años" (Ledesma y Tasso 2011: 86). Con frecuencia los "golondrinas" desconocen hacia dónde son llevados. Estos son algunos de sus rasgos característicos y sus efectos en la trama familiar:

- La marginalidad social de su contexto de origen, la privación relativa de capital cultural, y la subalternización que ellos provocan en el mercado de trabajo. 
- La explotación que conlleva el trabajo, con jornadas de trabajo en negro excesivamente prolongadas, las consecuencias sobre su salud (11), la falta de cobertura previsional y aportes jubilatorios, entre otros.

- En el caso de quienes trabajan estacionalmente por períodos prolongados (tres a diez meses/año) la residencia en el contexto laboral dificulta el mantenimiento de vínculos familiares y comunitarios.

- La relativa privación demográfica de varones en edad activa debilita la capacidad productiva.

- La seguridad y el sostén del hogar, el trabajo productivo y reproductivo doméstico recae sobre las mujeres y los niños (Tasso 2010: 79).

El trabajo de la desflorada se hace del siguiente modo: el maíz se siembra en surcos, espaciados a 70 u $80 \mathrm{~cm}$. de distancia. Los surcos pueden tener un largo aproximado de 1.000 metros o incluso mucho más. Se disponen 2 plantas machos cada 6 hembras y sólo a estas últimas se les quita la flor que, a su vez, son las únicas cosechadas.

"Cada integrante de la cuadrilla toma un surco, le quita la flor al maíz de las plantas hembra y la tira al suelo. Los obreros tardan alrededor de una hora en recorrer cada surco. Al llegar a la cabecera, si hay tiempo descansan 10 ó 15 minutos, y luego retoman por el surco aledaño realizando la misma operación. Mientras esperan que en un campo determinado aparezcan las flores que no han nacido aún, los peones toman otro predio. Son los ingenieros los encargados de indicar que la actividad ha finalizado (...) Una vez que finalizan de desflorar deben limpiar el campo. Es decir, quitar los yuyos que estorbarían la tarea o las llamadas plantas 'fuera de tipo'." (Desalvo 2009: 131-132).

Los primeros días, hasta que el cuerpo se adapta al intenso ritmo de trabajo, no hacen casi ningún tipo de actividad recreativa:

"En ese viaje me ha tocado una chala muy alta. A las 8 ya estábamos en cama, bien duritos quedábamos" (20, CE).

"La muñequeada le dicen: se te hincha la muñeca porque está en una posición muy incómoda todo el tiempo (...) algunos changos andaban escaldados, se te hace una cosa pelada entre las piernas, en el sobaco [axilas] porque te mojas y la ropa va rajando la piel. Terminas caminando con las piernas muy abiertas, muy arqueadas" (29, Sal).

Las viviendas son parte de los condicionantes que exigen del trabajador golondrina un gran esfuerzo de adaptación, por ser extremadamente precarias. Las casillas suelen ser de chapa, con camas cucheta; a veces, son construcciones de horcones con lonas a los costados y arriba. En otros casos, los empleadores instalan un gran carpón con camas tipo "catre" adentro. Un adulto (BB, 38) durmió en el mismo lugar, cada verano, con su cuadrilla en un galpón atestado de arañas.

"16 cuadrillas había... ¡Una sola bomba para sacar agua! A veces teníamos que hacer fila, y había que volver sin poder bañarse, así sucios nos teníamos que acostar. La carne te daban para que dure 3 días. ¿Cómo iba a durar 3 días sin heladera? (...) Sancochaban [pre-hervían] los cocineros para que dure un poco más, pero al tercer día el guiso tenía olor a podrido" (20, BB).

“¿Baño? Allá no hay baño ni ducha, vas al baño donde se pueda, casi siempre ahí nomás cagamos, en medio del maizal (...) [respecto de aviones fumigadores con aspersión de agroquímicos] Nosotros nos tiramos así al suelo, y estuvimos, así, un rato, hasta que la nube estaba y después ya se iba. Ese silbido en el pecho hace como tres años que lo tengo" (33, CE).

\subsection{Estrategias de control}


El cabecilla trabaja y supervisa a su cuadrilla. Transmite a los integrantes la expectativa de productividad esperada para rendir bien y recibir un buen puntaje. Este cabecilla es un TRME experimentado de los 40 a 60 años. El capataz supervisa y controla a varias cuadrillas, y a su vez el jefe de lote supervisa a los cabecillas. El capataz frecuentemente es un peón experimentado. En los terrenos de las semilleras internacionales, el repertorio de control consiste en varias estrategias: observarlos con binoculares desde la caja de una camioneta, esperar a los trabajadores al final del surco controlando el reloj para ver quien demora más, o incluso seguirlos "surco por surco". El tiempo del proceso productivo es exigente, ya que el lote está apurado, o la flor apura.

Hay un repertorio de control a jóvenes inexpertos: se identifica algún novato que refleje "amenaza" posible al mecanismo de rendimiento, se lo sigue y se lo increpa constantemente, hasta que el muchacho se "trabaje callado". Los otros evitan cometer el mismo "error". Para esto, opera el temor inminente del "despido" o de no ser contratados al año siguiente. En la desflorada uno se hace hombre, si no "a tu cuadrilla la ponen en rojo" (26, CE):

"Todos los días el capataz nos seguía con el tractor, hasta el cerco. Y se bajaba y nos seguía, surco por surco. En eso se me viene, tenía flores bajo el brazo, y me tira todas las flores, ahí a los pies. Y me dice: 'Mirá todo lo que has dejado', y te pone en vergüenza frente a todos" (30, CE).

"La cuestión es que tienes al capataz por atrás tuyo; y él no te reclama a vos, le reclama al cabecilla. Y la sanción es que te baja los puntos. [por ejemplo] si vos tienes chaleros, que son los tipos que dejan mucha flor, los que sacan la flor con mucha chala, [e capataz] le va reclamando al cabecilla, y... depende, lo que se le antoje a él, si quiere, 5 puntos, ponele, y te saca el premio" (28, Sal).

La empresa otorga un puntaje (1 a 10), con el cual cotiza la hora para cada uno de los integrantes de la cuadrilla. Por otro lado, los cabecillas reciben una bonificación según cómo haya trabajado su cuadrilla. Este mecanismo de control hará que el cabecilla se ocupe, con mayor rigor, de que su cuadrilla haga un buen trabajo y evite cualquier tipo de reclamo (Desalvo 2009: 137). Al parecer, el repertorio de control, quiebra el vínculo grupal que antes estaba armado por experiencias en común, la lengua o el parentesco, y ahora se establece por la eficiencia del "equipo". Aunque es un trabajo rural, el ambiente es identificable con modo industrial: "El capataz tenía una forma muy fiera de apurarnos. Nos decía: 'Pónganse a la par de los otros porque los están ganando'. Pero él no quería entender que nuestra cuadrilla éramos pichones todavía, los otros tenían más cancha" (26, CE).

La desflorada genera ciertos consensos conflictivos: no es lo mismo la opinión de un cabecilla experto que la de un integrante de cuadrilla novato. Un jefe de cuadrilla de 60 años manifestaba orgullo de su rol, al saber administrar los recursos alimenticios y laborales que le asigna el capataz. "Un cabecilla se mide por ser el mejor desflorador. Si vos te pones a criticar esto como trabajo, te dicen que sos un pecho frío (...) vos tienes que ser un profesional de la chala, a toda máquina" (29, Sal). Los trabajadores de más de 30 años explicitan un saber especializado, que les permite evaluar y "medir" a los más jóvenes: "son muy inútiles para hacer varias cosas y aprender. Antes vos dormías un mes en el suelo y no te pasaba nada. Ahora se resfrían o se desmayan en una semana haciendo desflorada" (40, CE). Algunos jefes de cuadrilla se identifican con la lógica laboral del empleador (Manpower y Satus Ager, entre otras multinacionales o locales). En una oportunidad, mediante encuesta para saber qué propuestas tiene para mejorar sus condiciones de trabajo, un cabecilla respondió: "quisiera que la empresa nos contrate todo el año".

\subsection{Conflictos sociolingüísticos}

Los aspectos negativos registrados son numerosos. Casi la totalidad de los TRME no pasa las fiestas de fin de año con sus familias. Sumado a los problemas de salud, las condiciones habitacionales y sanitarias, el agua no potable, provocan un cuadro de excesiva precarización laboral. Una táctica explícitamente "pícara", o la picardía como reacción (¿fugaz, subrepticia, intersticial?) a una asimetría laboral que algunos manifiestan como injusta, es la siguiente: 
"Yo te decía que el zorro puede ser cualquiera, cualquier hachero, cualquier hombre. Y sí, porque... yo te decía el otro día que un patrón, a lo mejor me dice a mí: "esta hectárea de tierra te pago" con decirte $\$ 500$, y sabiendo él que esa hectárea de tierra vale \$1.000 para limpiar (...) Y bueno: él es pícaro, yo también yo voy a ser pícaro (...) ¿qué le vas a hacer? Vos en vez de trabajarle, vas a hacer ese trabajo por 10 días, lo vas a hacer en 5. Pero ¿cómo? (...) Es cortarle la planta arriba, pero decirte arriba (significa) cosa que no se vea. $Y$ en vez de hacerlo en diez días lo vas a hacer en cinco, pero vamos a usar la picardía. Él (patrón) ha querido ser más pícaro que vos, pero vos sos más que él" (40, CE).

Lo llamativo de este caso (su picardía ante un empleador informal) es que se trataba de un cabecilla. Lo cierto es que el ejemplo muestra cómo un dispositivo de control sirve como disparador de acciones consideradas "ilegales" para el empleador.

Según los testimonios, el quichua es la lengua de uso mayoritario. Casi todos aseveran hablar quichua "casi siempre", en el horario laboral (de 9 a 14 hs. de trabajo), y en el horario de descanso (3 o 4 horas). En cuanto aparece el capataz o alguna persona extra-grupal, les hablan en castellano. El ambiente laboral es rígidamente jerárquico, pues casi siempre los TRME no pueden dirigirse al capataz, sino mediante el cabecilla (12):

"Un día estábamos hablando en quichua, y venía el capataz, y uno me dijo: 'Shhh, pará, que ahí viene el jefe', y teníamos que callarnos (...) El capataz viene, nosotros estábamos jugando a las cartas, y yo le digo: 'Buen día'. Y me dice: 'Con razón te tomas atribuciones vos'. Y me agarró desprevenido, pero le dije que en mi pago nosotros acostumbramos a saludar a la gente. 'Encima sos gallito, mirá vos', me dice. Saludar al capataz era una falta de respeto. No le tenías ni que mirarlo. Para eso estaba el jefe de la cuadrilla. El capataz es el jefe para la gente. Es muy estructurado eso, y no se puede cambiar nada" (26, CE).

Pero los usos lingüísticos se concretan, mientras se relacionan dinámicamente con ideologías lingüísticas. Es evidente que, en muchas ocasiones, el empleador asigna al quichua un valor que puede ser de amenaza, retraso en el ritmo, o poco rendimiento. En apariencia, no se permite ningún tipo de construcción contra-hegemónica, al menos en el plano de la lengua. No hay lugares posibles de liberación de la palabra, puesto que el ambiente, las condiciones laborales, y la coerción psicológica del capataz hacen que su esfera quichua sea sumamente ilegal.

La única forma de responder a las prohibiciones violentas es con alguna reacción, pero sus consecuencias repercutirían en las posibilidades laborales al año siguiente. Sabemos que este tipo de conflictos no es infrecuente: "Lo han hecho re cagar [golpearon al capataz]... eso sí, al año no volvían más, al menos con esa empresa" (26, BB). Esto supone que los conflictos violentos sí existen, y que las peleas con el empleador también son frecuentes.

“(..) el jefe -cabecilla- estaba con los changos tomando mate y hablaban en quichua. Y había uno, ése era muy quichuista (...) En eso viene el capataz y nos dice el chango que hagamos silencio, y yo le digo: ‘¿Y qué tiene?' Y me dice: 'Upallay, cha wayna creenqa que noqayku indius kanchu' (Callate, ese hombre creerá que somos indios)" (20, CE).

La identificación altamente conflictiva de este muchacho, se afincaba en una contingencia respecto de su lengua, incluso percibida como estado de peligro por no ser una marca "cotizable" en el espacio laboral. En esa comparación (quichua-indio) opera una ideología objetivista de la lengua, donde el quichua no puede ser asimilado al trabajo "calificado" y altamente eficiente de la desflorada. Nótese que este muchacho prohíbe hablar quichua, siendo él quichuahablante. Se asume en otra voz; en ese momento, toma para sí la prescripción y se asume como un sujeto activo de la institución que lo niega a su vez.

“De un estar, venía el jefe que hace 'recuento' de flores (13), y estábamos hablando en quichua con los brazos arriba en la flor. Y le dice 'Mansilla', y el muchacho quedó rojo, y dejó de hablar quichua conmigo. Le dijo: 'Fijate que allá falta desflorar', y mi amigo se ha ido adonde le decía (el jefe). Es 
como que le ha molestao (que estemos hablando quichua), qué se yo" (26, Sal).

Parece no haber espacio posible para "la quichua" con este tipo de capataces explícitamente prohibicionistas. Sin embargo es dicha, adentro del ambiente institucionalizante-industrializante de la desflorada, y aún con intenciones aleccionadoras a los novatos más "chaleros":

"Cuando andas en el lote, también te hacen burla, por ahí ¿has visto? Si te has quedao, te dicen 'walu ó, ancha marchaq apinki ó' (qué tortuga che, tienes que caminar más pues), por ejemplo. 'Che, kutipas yanasus' (che, el amigo se me lo ha quedado) dice así, 'kutipara pobrecito, chaqayp akuysh tinkunakoq', vamos a encontrarlo, se ha quedao el pobrecito. Es como decirle en quichua más diferente, es más como... genera en quichua como... como menos lascivo, ¿entiendes? Porque para un tipo que se queda lejos, es feo, es humillante" (30, Sal).

"Apurar" en quichua resulta más solidario que decirlo en castellano, una ideología subjetivista que introduce pedagógicamente a un novato en la hegemonía laboral. Un joven muy despierto, escolarizado hasta el secundario y con amplia experiencia cultural, "muy quichuista", fue quien explicitó como reclamo laboral:

"No se dan cuenta que el beneficio se lo llevan los otros. A mí no me han contao, yo he vivido en carne propia. Ahora quieren mejorar pero ¿y todo lo que hicieron antes, todo lo que dejó la gente? ¡Cuánta gente ha muerto en la desflorada y nunca han hecho juicio a nadie! Suponete que yo quiero hablar en la radio y decir estas cosas, la misma gente se te pone en contra si quieres decir algo. ¿Cómo haces para reparar el daño de tantos años?" (28, Sal).

\subsection{Socialización en el desmonte}

Permítasenos agregar esta comparación: hay otros tipos de trabajo migrante donde los "golondrina" venden su trabajo para empleadores particulares en contrato informal. Agregamos esta escena respecto del desflore para remarcar determinado "ambiente" lingüístico. Los controles laborales propios de empresas multinacionales, no existen en este contexto. En este caso, se trataba de terrenos cercanos a Tintina (dpto. Moreno, SdE).

En los videos filmados en celular por uno de los muchachos, se observan camas de palos y lonas, fuego donde hervía una pava, ropa colgada en los arbustos, mujeres, niños y muchachos sentados alrededor del fuego, conversando en algo que no pudimos identificar como frases en castellano. Según sus testimonios, casi siempre estaban hablando en quichua. Esto nos llevó a pensar los usos quichuas de un modo que no podíamos imaginar mientras realizábamos las entrevistas a TRME de la desflorada. Ni controles laborales ni prohibición lingüística de ningún empleador dado que éste se retira del lugar para abastecer de alimentos o herramientas. Esto significa que los ámbitos de uso quichua estaban "intactos" porque, sencillamente, estos trabajadores y sus familias (a pesar de las estafas de los precios, el abandono y el aislamiento geográfico) no modificaron en absoluto sus patrones discursivos cotidianos ni sus redes de sociabilidad vecinal.

\subsection{Picardías sociolingüísticas}

Muchas referencias al quichua parten de otros usos que no guardan relación explícita con conflictos, sino que nos indican la vinculación con una red de sociabilidad de origen, puesto que los integrantes de la cuadrilla son de la misma zona. Recordemos que el cabecilla busca golondrinas de confianza para el rinde eficaz del maíz.

En el espacio de ocio, tiempo libre es muy acotado, con actividades recreativas y de descanso sin intensidad. Suelen fumar, juegan a las cartas, se cuentan algunos chistes, se bañan o lavan su ropa. Si 
bien juegan a la pelota, ésta es una actividad prohibida por el capataz porque puede ocasionar golpes, y consecuentes problemas de rinde al día siguiente. En los últimos dos años, algunos jóvenes llevan equipos de MP3 para escuchar música en tiempo libre; no pueden escuchar en momentos de trabajo porque es incómodo acomodar constantemente el pequeño aparato y los cables, mientras están con los brazos levantados, constantemente, haciendo la desflorada.

"Uyarinku radiut, uyarinku, ari. Pero tuta, tutapi, puñunaas kan. [Escuchan radio, escuchan, sí. Pero de noche, cuando están queriendo dormir] (...) apanku, apanku radios, grabadores, kunan ancha achka tecnologías tiyan. Hasta pen drivet aparanku changos, música taka utkupi. Noqa aparani pen drive ka ancha achka música churapus. Por eso apin ka pen drive. Y chamamé, folclore, kan" (Ilevan, llevan radios, grabadores, ahora hay mucha tecnología. Hasta pen drive llevan los changos, adentro [va] saturado de música. Yo llevaba pen drive poniéndole muy mucha música. Por eso lleva ese pen drive [señala su aparato]. Y chamamé, folclore es)" (30, Sal).

Muchas veces se esconden objetos para hacerse bromas. Suelen llevar guitarra y bandoneón. En otra ocasión, tres muchachos se desafiaron mutuamente, en círculo y sentados, para ver cuál era más ingenioso en encontrarle "parecidos" al capataz del predio donde se encontraban, un ingeniero de mal carácter. Podríamos pensar que el quichua es un intersticio en horarios de ocio: en realidad ésta es lengua de uso mayoritario si en la cuadrilla más de la mitad son bilingües (14). Si es de uso minoritario, los bilingües aplican varias estrategias para hablar quichua entre ellos: se retiran a una pieza para sentarse a hablar, o se invitan "a caminar" o "ir al monte"; ésta última acción es para ir a orinar juntos en "el oscuro", mientras hablan en quichua lejos de la cuadrilla:

"Cuando los changos se están bañando, así, 'pishqoyki ancha wañerulu kan' (tu pene muy muerto está), como muerto así, como que está agonizando. O si no, te dicen: 'qaanaan utkut munan' (quiere mirarte el agujero), estee, 'ama agachakuy ima' (no te vayas a agachar), te dicen así, no te vayas a agachar así [risas]” (30, Sal).

Pero no sólo hablan en quichua en eventos graciosos, sino que también discuten en quichua sobre el cobro, o en asambleas, e incluso discuten sobre los políticos de sus pueblos:

"Ancha suk tema, particularmente suk tema ancha achka recurrido kunan, kara: pit kaq rin comisionado kunan? Pit comisionado ganaq rin? Bueno, chay noqa saqerani ideologiayta [risas]. $Y$ rimarani tukuy, sobre todo jóvenes... que cosasta deben cambiayta. (Un gran tema, particularmente un tema muy recurrido ahora, era: ¿quién va a ser comisionado? Bueno, ahí yo dejaba mi ideología [risas]. Hablaba a todos, sobre todo jóvenes... que las cosas deben cambiar) (30).

En otro caso, un jefe de cuadrilla comentaba que se reunían en grupo para informar directivas del capataz, o planificar el trabajo de la semana siguiente:

"Los integrantes de la cuadrilla eran amigos míos, todos de Cardón. Contaban cuentos, o se sentábamos a planificar cómo iba a ser el día lunes, todo en quichua. Todos hablaban en quichua. Cuando no estábamos trabajando, jugábamos a las cartas, o salíamos a cazar algún peludo para comer. 'Capaz que estábamos todos y no había personas ajenas, el 99 \% hablábamos en quichua'. Recién los domingos para hablar por teléfono [en castellano], los que no tenían celular" (40, CE).

De algún modo, ese 99 \% del quichua no sólo cumple un rol de cohesión grupal en la cuadrilla, sino que también es un resguardo psicológico, un "no estar tan lejos de casa" (15). El quichua es emitido casi en la totalidad del tiempo, con excepción de la presencia del capataz (dependiendo su proveniencia) o de otro supervisor.

Sobre el intercambio de narraciones, todos manifiestan que era en la desflorada donde más cuentos aprendían. En particular, muchos cuentos del zorro eran "intercambiados" antes de dormir, pero no consideraron que estos "casos" zorrunos tuvieran un valor "diferente" de otros cuentos. Son muy frecuentes las referencias a chistes de humoristas santiagueños, que a su vez sirven de disparadores de otros cuentos (16), que pueden ser o no bilingües. Muchísimos cuentos de animales y personas, 
pertenecen a una híper-trama narrativa con gran intensidad de picardía (Andreani 2011), donde lo erótico, atrevido, ladrón, pendenciero, etc., cruzan los relatos y sirven como factor de cohesión grupal. Según los testimonios, contarse cuentos es muy esperado: cuando alguien comienza a narrar, los demás se acercan inmediatamente. Es evidente que hay algo "especial" en esa atracción narrativa al interior del grupo, y que el aislamiento, el cansancio monótono del maíz y el control laboral colaboran en ese estado grupal, siempre de noche.

Agreguemos a esta trama laboral, lo que un abuelo refiere sobre los cuentos del zorro y "golondrinas" jóvenes: "El zorro no tiene estadía fija. Vamos a decir que el zorro tiene muchas picardías, y que el zorro es medio irretudo, ¿no? Porque es muy vivo en el andar, porque desposiciona su lugar" (72, CE). "Irretudo" refiere a una persona que siempre tiene mala suerte en sus cosas. Esto implica una identificación muy particular de sus pobladores con estos relatos, siempre en relación con su propia movilidad, su poca "suerte" laboral, y su deslocalización constante en el trabajo de la desflorada. La temática "golondrina" está ausente en los cuentos de animales, los cuales mantienen una estructura rígida que no permite grandes variaciones en su matriz. No se trata de encontrar elementos explícitos de la desflorada en los cuentos, sino de comprender cómo se identifica/se relaciona una comunidad bilingüe con sus propios relatos orales bilingües. La desflorada opera significativamente en estos relatos, no a nivel de referencia explícita en dichos cuentos, sino que la misma red de sociabilidad favorece determinada "transmisión" narrativa. El ambiente "pícaro" es determinante para un caudal narrativo importante, lo que dispara una intensa interacción en quichua.

\section{Reflexiones finales}

Varias cuestiones surgen del cruce de aspectos laborales rurales y sociolingüísticos. Vale comparar lo siguiente: hubo y hay otras trayectorias migracionales de santiagueños, principalmente de jóvenes mujeres y varones, que viajan periódicamente a ciudades de SdE o Buenos Aires por trabajos temporarios, residiendo con familiares (residentes permanentes). Si bien no lograban reconstruir el hábito de comunalidad (Brubaker y Cooper 2000) inicial de su lugar de origen, muchos trataron de reorganizar parcialmente sus antiguas redes de sociabilidad en dicha ciudad global. No obstante, esto fue posible por su movilidad social ascendente, que a su vez permitió organizar asociaciones folclóricas, volver frecuentemente a SdE, o participar en celebraciones religiosas rurales. La diferencia sociolingüística reside en que los TRME no alteran significativamente sus patrones discursivos en el ámbito de la desflorada, dado que las cuadrillas (en tanto redes de socialidad de vecinos, familiares y conocidos) mantienen los mismos ámbitos de uso que en sus territorios de residencia.

El dato inesperado sobre los TRME surge cuando se contrastan el control laboral (o mecanismos de prohibición lingüística) y los usos que efectivamente realizan en quichua. La desflorada es, en realidad, un ambiente intenso de socialización lingüística (Schieffelin y Ochs 1986) en quichua, con bilingües activos, pero también con un contingente importante de jóvenes que no se consideraban bilingües completamente, o bilingües pasivos (en diversos grados de dominio o seguridad discursiva) quienes, en medio de un contexto parcialmente prohibitivo, se socializan con intensidad en quichua. Por ejemplo, J. (un muchacho pueblerino que fue a trabajar con una cuadrilla) terminó entendiendo "algo de quichua porque no me quedaba otra". Este dato problematiza la idea del desplazamiento, porque varios factores favorecerían el mantenimiento y la adquisición bilingüe inclusiva. Recapitulamos las condiciones materiales de la trama laboral de la desflorada, y pedimos al lector un esfuerzo para imaginar:

- varones jóvenes y adultos,

- en un proceso de aislamiento geográfico,

- lejos y fuera del alcance de sus familias,

- con mecanismos de competencia laboral que los obliga a "bajar" el nivel de conflicto grupal que hubiere, 
- y los dispone a moverse con ciertos códigos de "grupo" unido, para no retrasarse en la desflorada y en el trayecto dentro del surco del maíz,

- trabajando en "silencio" para evitar la desconcentración de la mano desflorando correctamente,

- con relaciones de confianza entre cabecilla y cuadrilla, pues éste no llevaría jamás a golondrinas que no sepan trabajar, o sin conocer su rendimiento,

- la cuadrilla con actitudes de complicidad ante la presencia del capataz,

- una intensa interacción en quichua en momentos laborales sin el capataz,

- o de interacciones bilingües con un capataz bilingüe (santiagueño), en horario de la cena,

- y una intensa interacción quichua en momentos de descanso,

- este proceso, durante un período de 45 a 60 días; es decir, un tipo de migración de temporalidad acotada (Kerswill 2006).

Una significación muy intensa en el ámbito de desflorada es que el quichua es asociado por el empleador como algo "ilegal", algo que significa amenaza y falta de productividad en la desflorada; aunque no en todos, pues muchos capataces son santiagueños bilingües. Nunca se proponen transformar las condiciones laborales, pero su quichua puede significar inestabilidad hacia la desflorada como institución.

El quichua, visto de este modo, puede significar "amenaza" porque no puede ser un elemento procesado e integrado a las estrategias coercitivas frecuentes en plena desflorada. Lo único que el capataz (¿solo el monolingüe?) puede hacer es "apurarlos", porque se siente interpelado en horario de trabajo cuando se aleja de una cuadrilla para ir a controlar a otra. Precisamente, parte significativa de ese "silencio" que nombramos como título, es un control lingüístico producto del ritmo biológico del maíz: el capataz sostiene su argumentación desde el ritmo natural de la flor que los "apura", y no sólo por cuestiones "ideológicas" contra el quichua de los TRME.

Distinguimos varias ideologías sobre lo bilingüe: a) como conflicto desarrollado en horarios de control laboral, donde se explicita la mediación entre "hablar" quichua y la estructura social de cada uno de los actores -golondrinas y capataces- (Woolard y Schieffelin 1994); b) como generalizaciones que ocultan los usos efectivos del quichua (Gandulfo 2007): por ejemplo, cuando los entrevistados nos cuentan sobre la prohibición explícita de los capataces, pero también la relación puede ser mucho más amena y no tan unidireccional.

Desde la propia lógica del capataz, la eficiencia de las cuadrillas a su cargo es su responsabilidad, por lo cual debe responder al dueño del lote (su superior) quien, a su vez también es responsable laboralmente de todo. El "silencio" del golondrina, es táctica de silenciamiento ante el control laboral del capataz, pero también por la mecánica misma de trabajo: en el surco el oxígeno es escaso, la atención debe ser constante, y "hablar" desconcentra a la mano que desflora. El concepto de bilingüismo como ocultamiento táctico del quichua (Grosso 2008) ubica a un agente hegemónico que tiene el control de la mirada (el capataz), a quien no se debe llamar su atención.

Por un lado, este ámbito de uso (el silencio, el "apurar", la falta de oxígeno) refuerza un dispositivo de prohibición bilingüe. Por otro lado, el silencio permite a los TRME mantener una cordialidad aparente con el empleador y les asegura la posibilidad de seguir trabajando. Picardías sociolingüísticas, como tácticas del bilingüe en un terreno que no le pertenece, donde se des-posiciona constantemente.

Hasta aquí, un cuadro sociolingüístico donde el sector empleador ejerce un control, que para nosotros funciona como prohibición del quichua, percibido (no siempre) como amenaza. Pero lo llamativo de este cuadro descripto, es el "mantenimiento" del quichua. Se presenta una paradoja curiosa: la intensa 
prohibición lingüística de agentes laborales (capataz, jefe de lote) y naturales (la flor que apura y obliga al "silencio"), y la intensa socialización intra-grupal en quichua. Este "dato" contradice nuestras propias posiciones personales de compromiso con estos obreros rurales, y esto se convierte en reflexividad de nuestro propio proceso metodológico.

La trama socio-laboral nos está indicando algo contradictorio, al menos para nosotros: las condiciones del trabajo agrario neoliberal pueden llegar a funcionar como (o se convierten en un sorpresivo) factor de transmisión-mantenimiento de la lengua quichua. Esto podría matizarse con los datos de otros trabajos migrantes con empleadores particulares (como el caso del punto 5.3), donde no hay controles laborales propios de empresas multinacionales. Allí, no sólo las redes de socialidad extendida de las cuadrillas son las mismas que en sus lugares de origen, sino también los patrones discursivos bilingües, que no son alterados por el "control de rendimiento" de empresas o empleadores particulares.

Este artículo no pretende soslayar las condiciones infrahumanas sufridas por los TRME y (en la mayoría de los casos) el trato coercitivo de los empleadores multinacionales y particulares. No intentamos buscar subrepticiamente ningún tipo de sujeto político que esté ejerciendo acciones de "resistencia" (a través de la lengua minoritaria como marca de identidad política). Se trata de indagar, sencillamente, qué usos e ideologías operan en estas lenguas, en un contexto laboral muy particular. Tratamos de no idealizar al sujeto laboral, puesto que no todos estarían en contra de este trabajo forzoso: no olvidemos las opiniones de un jefe de cuadrilla, para quien la desflorada debería hacerse "todo el año", fuera de sus familias.

Todo esto debe ser también contextualizado, pues no debemos generalizar (en un modelo único) las diversas experiencias, durante 40 años, de más de 35.000 TRME santiagueños desflorando maíz a lo largo del territorio agro-productivo de Argentina. $\mathrm{Y}$ esto, dentro de un proceso migracional de larga duración (Braudel 2002), que incluso tiene orígenes coloniales en SdE (Farberman 1998, Lorandi 2000). Teniendo en cuenta que la sustitución lingüística "es un proceso que registra avances y retrocesos, cuyas características van cambiando en función de las circunstancias históricas en que se desarrolla" (Albarracín y Alderetes 2004: 90), el caso de los TRME sugiere una realidad compleja en tiempo presente dentro de su propio universo: situaciones muy diversas que no se restringen al viaje, el desflore, los controles laborales y la vuelta al hogar con dinero.

Nos centramos en varios aspectos clave: a) el ambiente de coerción, concreto y eficaz en el "rinde" de la flor; b), un refuerzo del ambiente de uso bilingüe de la red familiar extendida, que no sólo no perjudica la transmisión intergeneracional del quichua, sino que lo potencia; c) un intensivo "curso" de lengua quichua para personas que entienden quichua pero no lo hablan, y jóvenes monolingües en castellano, que se convierten en oyentes activos de quichua. Vale la pena contemplar las migraciones rurales estacionales como factor de inmersión lenta en la franja masculina, pero también como ambiente favorable para un bilingüismo plenamente activo en etapas tardías del ciclo vital, (es decir, ya como jóvenes adultos o adultos medios).

Si bien es importante, el mantenimiento del quichua dentro del sistema educativo, no debería ser el objeto excluyente del análisis sociolingüístico. Los procesos de socialización bilingüe son complejos y no se restringen a la franja infantil, sino a lo largo del ciclo vital (Hecht 2010). La desflorada, en tanto ambiente de socialización lingüística, puede ser determinante para la franja adulta masculina durante 10 hasta 40 años de su vida como trabajadores estacionales. En la suposición de que un TRME hable quichua intensamente durante 2 meses en la desflorada, y que después no hable quichua el resto del año (10 meses), no implica necesariamente un proceso de retracción de dicha lengua.

Consideramos ver no un bilingüismo sino varios tipos, cuyos perfiles situados no deben ser soslayados en estudios sobre desplazamiento. Incluso, considerar determinado tipo de migraciones de larga data (en tanto período histórico de larga duración, durante siglos) como un factor que no sea completamente negativo: no se trata de postular este proceso como positivo, sino de resaltar que el quichua se sigue hablando, y este sencillo hecho (sobre todo si lo miramos como proceso de larga duración) nos interpela a reflexionar hasta dónde esto es así por la implicancia de las migraciones estacionales, y no sólo a 
pesar de dicho factor como negatividad totalizante. El problema de fondo en los planteos sociolingüísticos denuncistas, es confundir la erosión "identitaria" con la supuesta pérdida de algunas partículas de la lengua minorizada. Para tantos miles de TRME durante décadas, "la temporalidad y las trayectorias de migración no han sido las mismas" (Hecht 2011: 11).

Todo esto sugiere que el trabajo migrante en Argentina podría ser considerado un factor muy importante de socialización lingüística, lo cual permite enriquecer significativamente la discusión sobre mantenimiento-desplazamiento lingüístico. En nuestro caso, el trabajo migrante rural estacional indica no sólo un mantenimiento (tal vez conflictivo) del quichua, sino también la inclusión de nuevos sujetos que adquieren comportamientos y competencias bilingües, o al menos de escucha activa como bilingüismo táctico.

Cualquier diagnóstico de situación sobre la vitalidad o peligro de una lengua, necesariamente tendrá que considerar este tipo de factores económicos-migracionales del sector poblacional estudiado. Una perspectiva antropológica-sociolingüística permite una mirada más compleja sobre la diversidad de bilingüismos que efectivamente se realizan, se construyen, se resignifican o se ocultan por múltiples razones. La mirada sociolingüística que proyecta inconscientemente la imagen de un inactivo bilingüismo diglósico (o la asimetría unidireccional entre una lengua y otra), debe ser problematizada por la diversidad de micro-procesos sociolingüísticos que realizan su conflictividad o armonía efectiva.

\section{Notas}

1. La realización de este trabajo fue posible gracias a una Beca tipo I de CONICET. Agradezco a los trabajadores migrantes contactados de los departamentos Figueroa y Salavina y a los estudiantes del colegio secundario "Leandro Vicente Taboada" (Figueroa), a Alberto Tasso (CONICET) y Agustina Desalvo (CONICET) por los datos aportados. Agradezco también la lectura atenta de Carolina Hecht (CONICET), José L. Grosso (UNCa), Lelia Albarracín (UNSE), Jorge Alderetes (UNT). A Eduardo Acuña (UNSE) por la revisión del abstract.

2. Adoptamos la siguiente convención para testimonios citados y otras referencias: BB (Bandera Bajada, dpto. Figueroa), CE (Cardón Esquina, dpto. Figueroa), Sal (Villa Salavina, dpto. Salavina), TRME (trabajadores rurales migrantes estacionales, QS (quichua santiagueño), SdE (Santiago del Estero). Los testimonios citados -todos varones- indican edad y proveniencia (28, Sal), categorías nativas en subrayado, los textos quichuas -de párrafo separado- en cursiva, nuestras traducciones al castellano en (paréntesis), y otras acotaciones paratextuales en [corchetes].

3. En enero de 2011, a partir de la agenda mediática sobre trabajos forzosos y precarizaciones a TRME, se neutralizaron las voces de los TRME y la complejidad que amerita este tipo de trabajos.

4. Los 5 departamentos (Atamisqui, Salavina, Loreto, Figueroa, San Martín) donde se realizaron 224 encuestas a TRME para un informe a la OIT (Ledesma y Tasso 2011), son de gran población bilingüe (cf. Alderetes 2001: 29).

5. En un hogar donde hay TRME, el ingreso económico promedio en el hogar, proveniente de dicho trabajo, es de un 55, 05 \% (Ledesma y Tasso 2011: 75).

6. Para una problematización más desarrollada hacia la postura sociolingüística de la "muerte o pérdida de la lengua", véase Dreidemie (2006).

7. Realizando extensas encuestas estructuradas a diez TRME (en CE y BB), participamos en el proyecto "Trabajadores Rurales Migrantes en Santiago del Estero" para el Ministerio de Trabajo y la OIT (2010), a cargo de los sociólogos Alberto Tasso y Reinaldo Ledesma. 
8. También recolectando información de manera discontinua (período 2006-2010) en mis actividades como docente rural en el dpto. Figueroa, pero más sistemático como trabajo de campo durante el 2do semestre de 2010, otoño de 2011 y verano de 2012. Durante el proceso, la lengua quichua no sólo era un asunto a ser indagado, sino que servía como lengua vehicular para entrevistar a los sujetos. Si bien poseo un nivel básico-intermedio sobre el quichua, me permitió evitar varios obstáculos y me facilitó enormemente el diálogo con bilingües.

9. Algunas garantías metodológicas: con tres TRME mantengo una relación de amistad desde hace años, a través de varias actividades compartidas (uno fue mi alumno del secundario; otro es un militante cultural en su pequeño pueblo -a quien colaboré con sus actividades radiales-; otro es un amigo a quien visito regularmente). Esto permitió sortear muchos obstáculos.

10. El concepto pertenece al sociolingüista catalán Lluís Aracil en las décadas del 60-70, para problematizar los postulados neutrales de la sociolingüística funcionalista norteamericana (véase Calvet 1997: 17).

11. El trabajo afecta negativamente al cuerpo de muchos modos: contacto directo con agroquímicos nocivos; vómitos y jaquecas por el calor, irritación ocular, picaduras de alimañas; dolor de espalda, hombros, manos y cuello; las manos sangran frecuentemente; retención urinaria. Hay que sumar el hecho de que no hay hospitales cerca, descuentan puntos en caso de enfermedad, y hay abandono de personas en algunos casos (véase Ledesma y Tasso 2011: 82).

12. Decimos "casi siempre", pues es lógico que no siempre el capataz es, en rigor, una persona intratable, muchas veces se generan lazos afectivos entre éste y los TRME.

13. Esta persona es otro de los actores coercitivos: su trabajo es hacer "recuentos" de flores no despanojadas, y a la vez su accionar "contable" ejerce control cuando el capataz está con otra cuadrilla.

14. Un trabajador calculaba que "si una cuadrilla hay más quichuistas, van a hablar quichua en todo momento. Pero si hay varios que hablen castellano nomás, casi no vas a escuchar que hablen en quichua, a menos que se vayan a una pieza a hablar [quichua]".

15. Hay trabajadores que no aguantan más de dos semanas trabajando porque extrañan la casa, y no soportan el ambiente sumamente "cerrado" del desflore del maíz. A estos muchachos se les dice "volvedores", despectivamente, porque "no tienen aguante".

16. Esto también fue observado con mucha intensidad en sus familias. Por ejemplo, en Cardón Esquina la identificación con el humorista Pochi Chávez es muy significativa, y es referencia obligada en las sobremesas familiares; a su vez, esto es un disparador narrativo que alterna asistemáticamente el bilingüismo: en ese ambiente pícaro e hilarante, los niños son activos quichua-oyentes sin prohibiciones (Andreani 2011).

\section{Bibliografía}

Albarracín, Lelia Inés

2009 La Quichua. Volumen 1: Gramática, Ejercicios y Diccionario Castellano-Quichua. Buenos Aires, Dunken.

2011 La Quichua. Volumen 2: Gramática, Ejercicios y Diccionario Quichua-Castellano. Buenos Aires, Dunken.

Albarracín, Lelia Inés (y otros)

1999 "Aportes para la enseñanza del quechua en el NOA", Actas III de las Jornadas de Lingüística 
Aborigen. Buenos Aires, Instituto de Lingüística, UBA.

Albarracín, Lelia Inés (Jorge R. Alderetes)

2004 "El Quechua en Argentina: El caso de Santiago del Estero", International Journal of the Sociology of Language, vol. 2004 (167). Walter de Gruyter GmbH \& Co. KG. ISSN 0165-2516.

2005 "La lengua quechua en el noroeste argentino. Estado actual, enseñanza y promoción", en Serafín Coronel Molina y Linda Grabner-Coronel, Lenguas e identidades de los Andes. Perspectivas ideológicas y culturales. Quito, Abya Yala.

Alderetes, Jorge R.

2001 El quichua de Santiago del Estero: Gramática y vocabulario. San Miguel de Tucumán, Universidad Nacional de Tucumán.

Andreani, Héctor

2010 "Wawqes Pukllas: Jóvenes bilingües y material didáctico en quichua", en VII Congreso internacional de Lenguas Aborígenes y Extranjeras. Facultad de Humanidades de la Universidad de Salta, 1, 2 y 3 de julio de 2010.

2011 Los relatos quichuas del zorro y sus hablantes. Significaciones, usos y conflictos. Tesis de grado en letras (Summa Cum Laude). Universidad Nacional de Santiago del Estero (mimeo).

Biaggi, Cristina (y otros)

2007 Mujeres que trabajan la tierra. Un estudio sobre las mujeres rurales en Argentina. Buenos Aires, Ministerio de Agricultura, Ganadería, Pesca y Alimentos.

Bialet Massé, Juan

1904 Informe sobre el estado de las clases obreras argentinas. La Plata, Ministerio de Trabajo de la Provincia de Buenos Aires, 2010.

Bravo, Domingo

1965 Estado actual del quichua santiagueño. Tucumán, Universidad Nacional de Tucumán.

Braudel, Fernand

2002 Las Ambiciones de la Historia. Barcelona, Crítica.

Briggs, Charles

1986 "Aprendiendo cómo preguntar. Un enfoque sociolingüístico del rol de la entrevista en las investigaciones en ciencias sociales". Cap. III, Learning how to ask. Cambridge: University Press. (Traducción de Silvina Otegui y Verónica Fernández Battaglia, revisión técnica de Corina Curtis. Cátedra de Lucía Goluscio).

Brubaker, Rogers (y Frederick Cooper)

2000 "Beyond identity", Theory and Society, no 29: 1- 47.

Calvet, Louis Jean

1997 Las políticas lingüísticas. Buenos Aires, Edicial.

Canal, Bernardo

1951. Ensayos sobre cultura y territorio: de la estructura mediterránea. Teoría de la ciudad argentina. Buenos Aires, Universidad Nacional de Quilmes, 2010.

Dargoltz, Raúl

2003. Hacha y quebracho. Historia ecológica y social de Santiago del Estero. Santiago del Estero, Marcos Vizoso Ediciones.

De Granda, German 
2001 Estudios de Lingüística Andina. Lima, Pontificia Universidad Católica del Perú.

Desalvo, Agustina

2009 "Los obreros santiagueños en el desflore de maíz. Proceso y condiciones de trabajo", Anuario del Centro de Estudios e Investigaciones en Ciencias Sociales, año 3, nº 3: 129-148.

Dreidemie, Patricia

2006 Estrategias discursivas de persistencia cultural: (dis)continuidad del Quechua en el "habla mezclada" de migrantes bolivianos en Buenos Aires. Tesis de maestría en análisis del discurso. Buenos Aires, Facultad de Filosofía y Letras, Universidad de Buenos Aires.

Duranti, Alessandro

2000 Antropología Lingüística. Madrid, Cambridge University Press

Farberman, Judith

1998 "El peso de la continuidad. Tierra, trabajo familiar y migraciones en Santiago del Estero. Un estado de la cuestión", Población y Sociedad, octubre nº 5: 165-186.

Gandulfo, Carolina

2007 Entiendo pero no hablo: El guaraní acorrentinado en una escuela rural: Usos y significaciones. Buenos Aires, Antropofagia.

Garret, Paul (y Patricia Baquedano-López)

2002 "Language Socialization: Reproduction and Continuity, Transformation and Change", Annual Review of Anthropology, vol. 31: 339-361.

Grosso, José Luis

2008 Indios muertos, negros invisibles. Hegemonía, identidad y añoranza. Córdoba, Encuentro Grupo Editor.

Hamel, Rainer Enrique

1995 "Conflictos entre lenguas y derechos lingüísticos: perspectivas de análisis sociolingüístico", Alteridades, nº 5 (10): 79-88.

2003 "Conflicto entre lenguas, discursos y culturas en el México indígena: Los procesos de desplazamiento lingüístico", Palavra, nº 11: 63-88.

Hecht, Ana Carolina

2010 Todavía no se hallaron hablar en idioma. Procesos de socialización lingüística en niños en el barrio toba de Derqui (Argentina). Múnich, LINCOM EUROPA.

Hecht, Ana Carolina

2011 "Un análisis antropológico sobre la migración y el desplazamiento lingüístico entre hablantes de lengua toba en Argentina", Gazeta de Antropología, 2011, nº 27 (1).

Karlovich, Atila

2006 "Oralidad y escritura. Orígenes y perspectivas de las letras quichuas santiagueñas", en Mario C. Tebes y Atila Karlovich (coord.), Sisa Pallana: antología de textos quichuas santiagueños. Buenos Aires, Eudeba.

Kerswill, Paul

2006 "Migration and language", en Klaus Mattheier, Ulrich Ammon y Peter Trudgill (eds.), Sociolinguistics/Soziolinguistik. An International Handbook of the Science of Language and Society. Berlin, De Gruyter: 229-240.

Landsman, Manuel Enrique

2000 "La lengua en la dominación política (del Quichua de Santiago del Estero)", VI Congreso 
Internacional de la lengua Quechua. Santiago del Estero, Argentina. 18 al 14 de octubre.

Ledesma, Reinaldo (y Alberto Tasso)

2011 "Empleo rural y migrante estacional en Santiago del Estero", en Reinaldo Ledesma, Jorge Paz y Alberto Tasso, Trabajo rural estacional de Santiago del Estero. Buenos Aires, Ministerio de Trabajo, Empleo y Seguridad Social-OIT.

Lorandi, Ana María

2000 "Constitución de un nuevo perfil social del Tucumán en el siglo XVIII", Boletín del Instituto de Historia Argentina y Americana "Dr. Emilio Ravignani”, 3ra serie, n² 21, 1er semestre: 99-133.

Lorenzino, Gerardo Augusto

2003 "Bilingüismo y migración urbana: el quechua santiagueño", Selected Proceedings of the First Workshop on Spanish Sociolinguistics. Ed. Lotfi Sayahi, 53-60. Somerville, MA: Cascadilla Proceedings Project.

\section{Makihara, Miki}

2005 "Being Rapa Nui, Speaking Spanish. Children's voices on Easter Island", Anthropological Theory, $\mathrm{n}^{\circ} 5$ (2): 117-134.

Neiman, Guillermo

2009 Estudio exploratorio y propuesta metodológica sobre trabajadores agrarios temporarios migrantes. Informe final de consultoría. Buenos Aires, Ministerio de Economía y Producción/ Secretaría de Agricultura, Ganadería, Pesca y Alimentos/PROINDER.

Schieffelin, Bambi (y Elinor Ochs)

1986 "Language Socialization", Annual Review of Anthropology, vol. 15: 163-191.

Sichra, Inge

2005 "El bilingüismo en la teoría, la idealización y la práctica: ¿dónde lo encontramos? Una reflexión sociolingüística sobre el contacto de lenguas", V Encuentro de Lenguas Aborígenes y Extranjeras, Universidad Nacional de Salta, 26 al 28 de mayo de 2005.

Stark, Louisa R.

1985 "Historia del Quichua de Santiago del Estero", en H. M. Klein y L. R. Stark (eds.), South American Indian Languages: Retrospect and Prospect . Austin (Texas), Universidad de Texas: 732-752.

Tasso, Alberto

2007 Ferrocarril, quebracho y alfalfa. Un ciclo de economía capitalista en Santiago del estero. 18701940. Buenos Aires, Alción.

2010 "Trabajadores rurales migrantes estacionales en Santiago del Estero". Informe de consultoría para el MTEySS-OIT.

Unamuno, Virginia

2004 "Dilemas metodológicos, preguntas de investigación", Estudios de sociolingüística, n 5 (2): 219 230.

2011 "Plurilingüismo y educación intercultural bilingüe: miradas en cruce", $X$ Congreso Argentino de Antropología Social. Buenos Aires, Facultad de Filosofía y Letras, UBA.

Voloshinov, Valentín N.

1992 El marxismo y la filosofía del lenguaje. Los principales problemas del método sociológico en la ciencia del lenguaje. Madrid, Alianza Editorial.

Woolard, Kathryn (y Bambi Schieffelin) 
1994 "Languaje Ideology", Annual Rewiew of Anthropology, n 23: 55-82.

Williams, Raymond

1977 Marxismo y Literatura. Barcelona, Península, 1997.

Wittig, Fernando G.

2009 "Desplazamiento y vigencia del mapundungún en Chile: Un análisis desde el discurso reflexivo de los hablantes urbanos", Revista de Lingüística Teórica y Aplicada. Concepción (Chile), 47 (2), II Sem.: 135-155. 